\title{
Las negociaciones con los cristianos nuevos en tiempos de Felipe III a la luz de algunos documentos inéditos (1598-1607)
}

\author{
Juan I. Pulido Serrano * \\ Universidad de Alcalá
}

En 1598 moría el rey Felipe II dejando tras de sí una monarquía en una situación de extrema gravedad. Los principales conflictos en el ámbito internacional seguían abiertos; las guerras en Europa y ultramar habían producido estragos en la economía peninsular. La bancarrota decretada por Felipe II en 1596 era la expresión más evidente de la quiebra producida y los reinos peninsulares, especialmente Castilla, mostraban signos de agotamiento. La hacienda del rey estaba bajo mínimos, con unas fuentes de recursos económicos hipotecadas, que poco o nada rendían ya a la Corona, pues lo principal de ellas iba a parar a manos de los acreedores del monarca. Tal era la situación en los últimos años del siglo, haciéndose célebre aquella frase que decía, de manera tan gráfica, si no muere el rey, muere el reino.

Murió el rey, y el ascenso de su hijo al trono en 1598 produjo un cambio radical en los principales asuntos de la monarquía. El primero de estos cambios afectó al equipo de ministros que venía trabajando junto al monarca. Fueron apartados de la corte los hombres que habían estado más cerca del rey difunto y, por el contrario, se asistió al ascenso de otros nuevos que pasaron a controlar la vida política. No sólo cambiaron los hombres, sino que además cambió el sistema de gobierno. La llegada del futuro duque de Lerma al corazón de la corte, convertido en favorito o

\footnotetext{
*jignacio.pulido@uah.es
} 
privado del rey, marcó un cambio profundo en el modelo de gobierno, iniciándose el sistema político del valimiento, que con algunos antecedentes en el pasado, iba a perdurar durante todo el siglo XVII. Un nuevo sistema que, además, iría acompañado de una nueva manera de gobernar, ahora a través de las conocidas juntas, que desplazarían a la tradicional fórmula de los consejos que venían funcionando desde el inicio del siglo XVI. Juntas de gobierno constituidas ad hoc, por decisión del rey, aconsejado por su valido, cuya función era tratar cuestiones concretas que afectaban a los intereses de la monarquía, disueltas una vez concluido su trabajo e integradas por ministros conocedores del asunto en cuestión.

Estas juntas, formadas por un reducido número de ministros de reconocida fidelidad al valido, el duque de Lerma, gozaron de una extraordinaria capacidad de decisión política y de plena jurisdicción sobre los temas que trataron. De ahí la oposición que levantó su trabajo entre los órganos e instituciones tradicionales de gobierno, los consejos, y la antipatía general que se granjearon en la época. Sin embargo, la urgente necesidad de encontrar soluciones a los problemas graves y el apremio que existía, aconsejaban que se aplicaran medidas inmediatas, algo que por otro lado difícilmente podía garantizar el sistema de gobierno polisinodial, complejo y lento, que agotaba buena parte de sus energías en disputas protocolarias y en la actividad judicial, resolviendo innumerables pleitos, lo que iba en detrimento de sus tareas de gobierno.

Además, para el valido era más satisfactorio el trabajo con las juntas, controladas por él y compuestas por gentes de su confianza. Los ministros de los Consejos, sin embargo, eran de difícil manejo y se prestaban fácilmente a dar salida a las permanentes corrientes de oposición. Aunque desde el inicio de su valimiento Lerma consiguió que fueran entrando en ellos sus hechuras, éstas tenían que compartir el espacio con ministros que venían del reinado anterior y que se resistían a la sujeción. Además, los proyectos políticos del valido tenían mayor garantías de éxito cuando evitaban en su tramitación a los consejos, pues aquí solían naufragar.

\section{EL DESEMPEÑO DEL REINO}

En el inicio del reinado de Felipe III, en 1598, el problema más angustioso y que exigía una urgente solución era el que afectaba a los apuros de la hacienda. El Duque de Lerma se propuso desde el inicio 
de su privanza atajar esta espinosa cuestión, y para ello se valió de una serie de juntas creadas con ese objetivo. Escogió un grupo pequeño de ministros de su hechura, los cuales formaban su equipo más íntimo de colaboradores. Destacó por encima de otros, don Pedro Franqueza, hombre de su absoluta confianza y cercanía, a quien le proporcionaría el título de conde de Villalonga; también sobresalieron el Licenciado Alonso Ramírez de Prado, don Rodrigo Calderón y Pedro Álvarez Pereira. Sobre estos personajes, especialmente sobre el primero de ellos, nos ocuparemos de forma extensa a lo largo de estas páginas, por el protagonismo que tuvieron en lo referido a las negociaciones con los cristianos nuevos portugueses y en la política seguida en esta cuestión entre los años 1598 y 1607.

A finales del año de 1600 se creó una junta de gobierno encabezada por Lerma en la que también participaba Pedro Franqueza y que tenía como objetivo tomar el timón de la monarquía para introducir un conjunto de reformas ${ }^{1}$. Las extremadas dificultades financieras de la monarquía llevaron a la creación por esas mismas fechas de una junta de hacienda que debía buscar la manera de sanear las cuentas del estado. Pedro Franqueza, más un pequeño grupo de ministros entre los que también estaba Ramírez de Prado, formaban parte de esta junta ${ }^{2}$. Una de sus resoluciones, elevada al rey, fue la creación de otra junta con el objetivo de conseguir desempeñar los recursos económicos de la Corona, hipotecados la mayor parte de ellos. Tendría plena jurisdicción sobre todo lo relativo a las rentas y derechos que pertenecían al rey y se les autorizaría a buscar nuevas fórmulas con las que acrecentar los recursos del erario.

Nacía así en 1603 la Junta de Desempeño General del Reino, y tenía tres años como plazo para alcanzar sus fines; desapareció en 1606 sin haberlo conseguido y bajo graves acusaciones. La Junta de Desempeño asumió funciones plenas y autoridad absoluta en la toma de decisiones y en su ejecución. Los ministros que la componían eran Pedro Franqueza, Alonso Ramírez de Prado, el confesor del rey, los presidentes de los Consejos de Castilla y Hacienda y un secretario. La encabezaba el propio Lerma, aunque no solía asistir a sus sesiones de trabajo, valiéndose de Pedro Franqueza para estar al corriente. Este último era el hombre fuerte

1 A. Feros, El Duque de Lerma. Realeza y privanza en la España de Felipe II (Madrid 2002), pág. 234 y ss.

2 Feros, El Duque de Lerma, págs. 289-293. 
y principal en la junta. Él condujo los trabajos y preparó las decisiones de manera muy personal como más tarde se supo ${ }^{3}$.

Las competencias que asumió la junta, controlada por Pedro Franqueza, fueron extraordinarias, lo que dio a este ministro un poder enorme. Bajo su autoridad estaban la Junta de Hacienda de Castilla y la Junta de Hacienda de Portugal, situadas ambas en la corte y creadas poco tiempo atrás. Por ellas pasaba todo lo relativo a las cuestiones económicas de ambos reinos y gozaban de plena jurisdicción sobre las materias que trataban. Así, la Junta de Hacienda de Portugal en Madrid tuvo como objetivo, entre otras cosas, negociar con los banqueros portugueses nuevas líneas de financiación. Pedro Franqueza también era miembro de estas juntas, coordinando los trabajos de todas ellas. Por su parte, el Consejo de Hacienda en España y el Consejo de Fazenda portugués fueron sometidos a este nuevo sistema, obligándoles a ceder buena parte de sus competencias, no sin mostrar resistencia ante la marginación que sufrieron y ante lo que se entendía como una usurpación de su autoridad por parte de Pedro Franqueza ${ }^{4}$.

Pedro Franqueza, conde de Villalonga, era así el ministro más importante en lo referido a las cuestiones financieras de la monarquía. Contaba, además, con un notable margen de maniobra en lo que tocaba la toma de decisiones. Entre otras materias, por él pasaba la firma de los asientos con el rey, los contratos de arrendamiento de las rentas reales o el desarrollo de nuevos arbitrios para allegar recursos a la hacienda. Todo ello merced al protagonismo que jugó en estas juntas y a la confianza que en él había depositado el valido del rey. El favorito del valido; así se le conocería y como tal actuaría.

Este ministro, de origen catalán, había hecho carrera en la administración de la Corona de Aragón y gracias a la protección de Lerma consiguió medrar en la corte de Felipe III. Acumuló cargos por voluntad del valido: secretario de la reina, secretario del Consejo de Estado, secretario del Consejo

3 J.-M. Pelorson, «Para una reinterpretación de la junta de desempeño general (16031606) a la luz de la visita de Alonso Ramírez de Prado y de don Pedro Franqueza, conde de Villalonga», en Actas del IV Symposium de Historia de la Administración, Colección de Estudios de Historia de la Administración (Madrid 1983), págs. 613-627.

4 D. J. Martín Gutiérrez, La Junta de Hacienda de Portugal (Pamplona 1996), págs. 221 y ss. Este trabajo, muy bien documentado, reproduce en los apéndices información fundamental. 
de la General Inquisición. Un cronista decía que él «estaba apoderado de la máquina de todos los negocios importantes». A pocos se les escapaba que la mejor vía para hacer progresar las cosas en la corte era ganarse el apoyo de este ministro. Especialmente si de lo que se trataba era de algún negocio referido a cuestiones financieras: asientos, rentas o arbitrios.

Este nuevo sistema creado para dirigir la política financiera estaba afectado de un fuerte personalismo, lo que derivó en prácticas arbitrarias y en consecuencia, en la extensión de comportamientos corruptos. Fue de tal dimensión el fenómeno de corrupción y el escándalo que causó que finalmente Pedro Franqueza y Ramírez de Prado acabaron presos bajo la acusación de centenares de delitos. Lerma nada pudo hacer por ellos y para salvar su complicada posición dejó hacer. En diciembre de 1606 se detuvo a Ramírez de Prado y en enero de 1607 a Pedro Franqueza, acabando aquí sus carreras políticas. Los procesos que se incoaron contra ellos contienen miles de páginas y son, sin duda, una fuente documental de enorme valor para entender cómo fue aquel preciso periodo desde el punto de vista político y económico, además de arrojar detalles preciosos sobre muy diversas materias de la época.

\section{Las fuentes: el proceso contra Pedro Franqueza}

La rica información que he encontrado esparcida por los folios de los trece tomos que comprende la visita realizada por la Cámara de Castilla a estos dos ministros me ha permitido conocer cómo fue el trato de Pedro Franqueza con los hombres de negocios portugueses en general y con los cristianos nuevos en particular entre 1598 y 1607. Tras su lectura se deduce con toda claridad que él fue el principal ministro en las negociaciones que con los cristianos nuevos portugueses se desarrollaron en la corte en esos años, tendentes a introducir una serie de reformas legales que serían de extraordinaria importancia en la historia de este problema. Hoy hay común acuerdo en señalar que estos años marcaron un hito en la evolución secular del fenómeno converso, por la política que se ensayó entonces, aunque poco sabemos sobre los debates y las negociaciones que hubo en la corte y que hicieron posible una nueva forma de enfocar la cuestión.

De la documentación estudiada se desprende una primera certeza. Todo el asunto pasó por las manos de Pedro Franqueza. Él fue quien 
posibilitó las medidas tomadas entonces y, además, la evolución de las negociaciones marcharon aparejadas a su persona, corriendo similar suerte, pues la caída de este ministro en 1607 significó también el fracaso de la política emprendida y un brusco cambio y marcha atrás. Bien es cierto que todo esto hay que explicarlo en un contexto general que influye decisivamente en el transcurso de las cosas: fueron los días de la Tregua de los Doce Años en la guerra contra Holanda (1609), de la expulsión de los moriscos de España (1609), de la primera bancarrota del reinado (1607) y de la grave crisis en el régimen político creado por el valido (1606-1607). Pero examinando con detalle las negociaciones relativas a los cristianos nuevos portugueses, descubrimos la figura de Pedro Franqueza de forma omnipresente. Quedaría, esos sí, por conocer cuál fue el grado de implicación de Lerma en todo este asunto y, si como parece por los documentos estudiados, quedó al margen, dando autoridad a Pedro Franqueza para hacer y deshacer.

En concreto, entre este conjunto de papeles aparece un cuadernillo con casi medio centenar de páginas donde se recogen los interrogatorios que se hicieron a varios de los portugueses que de una manera u otra participaron en las negociaciones desarrolladas en la corte en relación a los cristianos nuevos. Durante el mes de Febrero de 1607, un secretario de la Inquisición llamó ante sí a cinco destacados portugueses que por entonces residían en Madrid. Estos interrogatorios eran parte de la visita que estaba instruyendo la Cámara de Castilla por orden del rey para conocer sobre las acusaciones que había contra los ministros Pedro Franqueza y Alonso Ramírez de Prado. El secretario de la Inquisición quería saber, en concreto, cuál había sido la relación entre unos y otros, y si en esta relación había habido algún tipo de delito.

Los interrogados fueron Martín Álvarez de Castro, Jorge Rodrigues Solís, Afonso Gomes, Jacome de Olivares y Pedro Gomes Reynel, todos ellos destacados hombres de negocios lisboetas. Los cuatro primeros llegaron a la corte como procuradores de los cristianos nuevos portugueses, con los poderes correspondientes en sus manos y con una comisión concreta a realizar. A partir de estos interrogatorios y con alguna otra documentación complementaria he tratado de analizar cómo se llevaron a cabo las negociaciones en la corte, con qué ministros se trató y cuáles eran los objetivos a alcanzar. De esta documentación y otra que aparece en los demás tomos de los procesos se desprende también mucha otra información que nos habla de la relación entre el go- 
bierno y los asentistas y hombres de negocios portugueses, tema que estudiaremos en otro lugar ${ }^{5}$.

\section{LOS PRIMEROS PASOS EN LA NEGOCIACIÓN (1598-1600): el procurador Martín Álvarez de Castro}

Martín Álvarez de Castro fue el primero de todos en ser llamado a declarar. Era caballero de la Orden de Cristo, natural de Lisboa y de 48 años de edad. Cristiano nuevo, a decir por algún panfleto de época posterior ${ }^{6}$. Era un experto en lo tocante a la hacienda de Portugal, merced a los oficios que había desempeñado: fue secretario de la Casa de la India en Lisboa y también de la Alfandega radicada en esa misma ciudad. Había venido a la corte a petición del rey para informar sobre la situación de la hacienda regia en aquel reino. Todo lo relativo a esta cuestión lo traía escrito en un libro de caja. Se declaraba, además, «muy amigo de Franqueza». En verdad, aquella amistad se tradujo por esos días en un permanente servicio. Martín Álvarez de Castro ayudó mucho a Pedro Franqueza en cuestiones muy delicadas, tanto personales como del servicio de Su Majestad. Él era quien iba de parte de Franqueza a hablar con este o aquel portugués, para proponerle algún asunto, el arriendo de una renta regia o un asiento con la Corona, la petición de algún préstamo o cosas un tanto turbias.

Explicaba Martín Álvarez de Castro que antes de partir de Lisboa camino de la corte «le visitaron los más graves hombres de negocios de Portugal, que a la saçón había en Lisboa»: Hector Mendes, Afonso Gomes, Francisco López, Diego Núñez Caldera, Antonio Nuñez Caldera, Gabriel Ribero de Acosta y otros «de la nación de los cristianos nuevos». Querían encomendarle una importante comisión. Debía ganarse en la corte a alguno de los ministros más destacados, y hacer llegar al rey a través de él una carta en la que se pedía de Su Santidad un perdón general para los cristianos nuevos de Portugal. A cambio, éstos estaban dispuestos a ofrecer un servicio de 620.000 ducados. Para allanar el camino y ganarse

5 Archivo General de Simancas (AGS), Cámara de Castilla, leg. 2796, nº 9, fols. 134r-156r.

6 A. Borges Coelho, Inquisição de Évora (Lisboa 1987), vol. II, pág. 203. Apéndice 18: «Males que acontecerem a todos aqueles que advogaram o perdão geral de 1605 ». 
voluntades en la corte, le dieron además 200.000 ducados, una cifra cuantiosa «para repartir por los ministros más importantes».

Una vez en la corte fue a visitar al Adelantado de Castilla, noble principal con quien tenía gran amistad desde que su padre, Lorenzo Mendez Castro, fuera servidor y criado de aquél. El Adelantado de Castilla fue uno de los nobles que participó más activamente en el régimen del duque de Lerma. Emparentó con él a través del matrimonio entre los hijos de ambos. En el mismo mes de la subida al trono de Felipe III, septiembre de 1598, Lerma promocionó al Adelantado de Castilla, consiguiendo que el rey le nombrase miembro del Consejo de Estado. Fue el Adelantado quien guió a Álvarez de Castro en la corte, llevándole a visitar a los principales ministros del rey.

En varias ocasiones ambos se reunieron con el Presidente del Consejo de Castilla, Rodrigo Vázquez, y con el Padre Cicilia. En cierta ocasión, encerrados largo tiempo en un aposento, Martín Álvarez de Castro explicaba lo abundantes que eran las rentas del rey en Portugal y lo poco que llegaba a sus arcas, por la mala administración, decía, y por lo que le hurtaban unos y otros; el Presidente del Consejo de Castilla, atónito, «daba palmadas sobre el bufete diciendo que de esto [de la hacienda del rey en Portugal] no iba al rey un solo real y que antes sea menester llevar dineros de Castilla para Portugal» ${ }^{7}$. Esta idea fue compartida por muchos de los ministros de Felipe III y Felipe IV, entre quienes existió el convencimiento de que aquel reino, pese a ser muy rico, pocos beneficios le daba al rey, por lo que era necesario buscar nuevas fórmulas para optimizar la llegada de recursos. Esta fue la idea que llevó a la creación de la Junta de Hacienda de Portugal en Madrid en 1600, con la destacada presencia de Pedro Franqueza en ella, y el envío de una comisión de ministros castellanos a Lisboa entre 1601 y 1605, donde ejerció como brazo ejecutor de la anterior.

En otro de estos encuentros, Martín Álvarez de Castro se atrevió a explicar al Presidente del Consejo de Castilla la petición que hacían los cristianos nuevos de Lisboa y el servicio que harían a cambio del perdón general. El Presidente Vázquez quedó convencido y desde entonces se convirtió en uno de los mejores valedores de este negocio. Habló de ello con el rey y con su valido el duque de Lerma. Tras la conversación, el

\footnotetext{
${ }^{7}$ AGS, Cámara de Castilla, leg. 2796, nº 9 fol. 136r.
} 
rey dio su autorización para que se abrieran negociaciones formales con los cristianos nuevos de Lisboa. Así, el Almirante de Castilla escribió a Hector Mendes, el principal promotor de aquella iniciativa, hombre extraordinariamente rico, cuya hacienda sobrepasaba los 800.000 ducados según se cita en estos documentos. Éste se reafirmó en su oferta y ofreció al Adelantado 100.000 ducados de comisión por su inestimable ayuda ${ }^{8}$.

El duque de Lerma quiso ganarse el apoyo del confesor del rey, fray Gaspar de Córdoba, en favor de la iniciativa llegada de Lisboa. Cuando Martín Álvarez de Castro y el Adelantado de Castilla hablaron al confesor, éste se mostró favorable, aunque sugirió que podría obtenerse más dinero por esta merced. A su vez, el Presidente del Consejo de Castilla Vázquez escribió al Inquisidor General de Portugal pidiéndole información detallada sobre el número de presos, estados de sus procesos y calidad de sus haciendas, con el fin de hacer una valoración ajustada de las consecuencias que tendría el perdón general en el fisco inquisitorial. Lo que consiguió fue dar la voz de alarma en Portugal, donde se movilizaron para hacer llegar sus protestas al rey.

Para ello se valieron del Consejo de Portugal, sito en la corte, donde varios de sus ministros, el Obispo Capellán Mayor (don Jorge de Ataide) y Pedro Barbosa, pero sobre todo Pedro Álvarez Pereira, hicieron lo posible para neutralizar las negociaciones. Detrás de ellos estaba don Cristóbal de Moura, primer marqués de Castelrodrigo, hombre clave, aunque en la sombra, en la resistencia a cualquier concesión a los cristianos nuevos. Cristóbal de Moura había sido el principal ministro de Felipe II durante los últimos años de su vida, y éste quiso que lo siguiera siendo de su hijo. Así se lo dijo en las instrucciones que le dio antes de morir: «Yo me hallo bien con don Cristóbal de Moura y con los demás que traigo a mi lado en los negocios. Así confío que os hallaréis vos, si os sabéis servir de él y

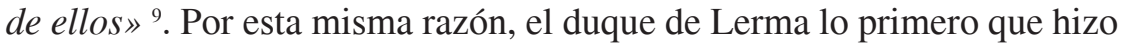
tras alcanzar el valimiento del nuevo rey fue procurar la marginación de este ministro. No fue fácil y sólo lo consiguió una vez que se le sacó de la corte tras su nombramiento como virrey de Portugal, cargo que ocupó entre 1600 y 1603. Hasta su salida de Madrid, Cristóbal de Moura continuó ejerciendo una considerable influencia en el Consejo de Portugal y, también, en el Consejo de Estado, de los que formaba parte. Él, junto a los

\footnotetext{
8 Ibid.

9 Feros, El Duque de Lerma, pág. 100.
} 
portugueses Pedro Barbosa, Pedro Álvarez Pereira y al Obispo Capellán Mayor, formaban la vieja guardia del Consejo de Portugal; todos ellos se situaban bajo la autoridad moral de Moura ${ }^{10}$.

Estos ministros portugueses solicitaron audiencia con el Presidente del Consejo de Castilla, que se negó a recibirles. Con el confesor regio tuvieron más suerte. Le pidieron «de rodillas» que aconsejara al rey la suspensión de las negociaciones con los cristianos nuevos portugueses. Pero el Presidente de Castilla volvió a hablar con el rey, haciendo una contundente defensa de la licitud del negocio desde el punto de vista moral y político, y finalmente le rogó que al menos lo consultara con el Consejo de Estado ${ }^{11}$.

Así se hizo. La discusión en el Consejo de Estado, máximo órgano político en la corte de la monarquía, tuvo lugar en diciembre de 1598. Se debatió sobre las consecuencias políticas de esta medida, pues sobre las cuestiones de conciencia ya habían dado su opinión algunos teólogos de relieve. En el consejo hubo cuatro puntos de vista. El principal fue el de don Cristóbal de Moura: fue el primero en tomar la palabra y habló en contra del pretendido perdón general con muchas razones, medida a la que se opuso siempre el difunto rey -dijo- por los graves inconvenientes que contraía. Además, aconsejaba que se consultara con los gobernadores de Portugal y con el Inquisidor General de allí. Después hablaron los ministros de la vieja guardia, Juan de Idiáquez y el Conde de Cinchón, sumándose a la opinión de Moura. El Presidente del Consejo de Castilla, Rodrigo Vázquez, y el Conde de Fuensalida, hombre de Lerma, apoyaron la concesión del perdón general a cambio del servicio prometido. Se quedaron solos. Otros dos de los hombre fieles al valido, el Duque de Nájera y el Conde de Miranda, aconsejaban mantener «en secreto el negocio, sin hurgarle más», y escribir al embajador en Roma para que tantease cómo se recibiría allí la posible

${ }^{10}$ S. LuXán Meléndez, La revolución de 1640 en Portugal, sus fundamentos sociales y sus caracteres nacionales. El Consejo de Portugal: 1580-1640 (Universidad Complutense de Madrid 1988). Este trabajo es, antes que nada, un estudio muy detallado de la evolución del Consejo de Portugal. Sobre el papel de Cristóbal de Moura en el consejo pueden verse los capítulos 4 y 5 . Sobre las complicadas relaciones entre el duque de Lerma y don Cristóbal de Moura en esos años sigue siendo muy útil el detallado trabajo de A. Dánvila Burguero, Don Cristóbal de Moura, primer Marqués de Castel Rodrigo (Madrid 1900), págs. 757-784.

${ }^{11}$ AGS, Cámara de Castilla, leg. 2796, nº 9, fol. 136vto. 
petición; mientras tanto, lo mejor era esperar. El rey escribió su contestación al margen de la consulta: «yo había hecho encomendar a Dios este negocio, y cuanto más resuelto estaba a no tratar de ello, me he holgado de lo que ha parecido a la mayor parte» ${ }^{12}$. El negocio parecía cerrado y así se hizo ver, aunque con el mayor secreto posible se dieron instrucciones al embajador en Roma para que fuera conociendo cuál era la sensibilidad allí ante esta cuestión.

Los hombres de negocios de Lisboa planearon una nueva estrategia. Escribieron a Martín Álvarez de Castro diciéndole que estaban dispuestos a aumentar la cantidad del servicio ofrecido al rey, como en su día aconsejara el confesor regio. También estaban dispuestos a aumentar los regalos y comisiones entre los ministros de la corte. El Adelantado de Castilla, volcado en el proyecto, convenció a Martín Álvarez de Castro para que siguiera a la corte en el viaje que hizo en 1599 a Valencia y Barcelona, donde debían celebrarse cortes para la jura del nuevo monarca. Le recomendó que se llevara consigo al Padre Cicilia por la ayuda que le prestaría y que se dirigiera directamente a Lerma para tratar estos asuntos. El propio Adelantado de Castilla navegó desde el Puerto de Santa María hasta Barcelona, con el objetivo de forzar al confesor regio a que se comprometiera en favor del proyecto y para que hablara al monarca en este sentido.

Durante las jornadas del largo viaje del rey y su corte por el Levante español hubo frecuentes encuentros entre Martín Álvarez de Castro y los principales ministros del monarca. Por estos días se consolidó su trato cercano y amistoso con don Pedro Franqueza, ayudándole en múltiples y delicadas gestiones, negocios de su propia casa y también de la Corona. Esta amistad le facilitó el encuentro con Lerma, de tan difícil acceso, imposible para muchos y con quien otros mantenían audiencia tras meses de espera. En cierta ocasión, Lerma le dio instrucciones a Martín Álvarez de Castro para que regresara a Madrid y una vez allí entrara en contacto con la Junta de Hacienda que se estaba celebrando en la casa del Presidente del Consejo de Hacienda. A ella se había enviado la propuesta de los cristianos nuevos para su discusión. Pero había un escollo difícil de superar. De acuerdo a las propias palabras de Martín Álvarez de Castro, el negocio no conseguía avanzar por la oposición que hacían los portugueses del Consejo de Portugal, muy especialmente a través de su secretario,

${ }^{12}$ AGS Estado, leg. 2636, nº 16 (Consulta de Diciembre de 1598). 
Pedro Álvarez Pereira. Él también era miembro de la Junta de Hacienda de Portugal, donde hizo valer su opinión y, de forma indirecta, la de don Cristóbal de Moura, con quien mantenía una estrecha relación ${ }^{13}$.

Entre 1598 y 1599 había quedado en evidencia que a pesar del apoyo de Lerma a las peticiones de los cristianos nuevos, su negociación no podía discurrir por el canal ordinario de los consejos sin serios riesgos de ver cómo se frustraba. En la corte, los Consejos de Portugal y de Estado habían conseguido de momento su bloqueo, y eso a pesar de la profunda reforma a la que Lerma los estaba sometiendo y a la incorporación que había propiciado de nuevos consejeros de su hechura en una y otra instancia ${ }^{14}$. Lerma sólo podría sacar adelante sus propósitos si conseguía antes la marginación de estos organismos de la vida política en la corte; debía, también, consolidar un sistema paralelo, el de las juntas, a través del cual conducir las negociaciones. Había que evitar además interferencias entre un sistema y otro, y para ello era fundamental afinar en la selección correcta de los ministros que integrarían las juntas. Este fue el camino que eligió Lerma para el desarrollo de su acción política durante los primeros años de su valimiento. En el caso de las peticiones de los cristianos nuevos portugueses, con el perdón general incluido, hubo que encaminarlas por esta vía.

Además, entre los años de 1598 y 1600 se había organizado en Portugal una sólida ofensiva contra las pretensiones de los cristianos nuevos. De manera coordinada se pusieron a trabajar la Inquisición, la máxima jerarquía eclesiástica y los Gobernadores de Portugal. A principios del año 1600 acordaban que el reino haría un servicio a la Corona de 800.000 cruzados a cambio de que el rey no aceptase las peticiones de los procuradores de los cristianos nuevos. Felipe III aceptó la oferta y don Cristóbal de Moura, desde Lisboa como virrey, le escribió agradeciéndoselo: «La bendición de Dios aya Vuestra Majestad y también le alcanzará la de su padre que dejó de hacer este negocio, porque le dijimos que no podía lucir

${ }^{13}$ AHN Estado libro 81, fols. 55r-70vto. Se recogen aquí varias cartas que ambos se intercambiaron entre 1600 y 1601, en las que se puede apreciar la evolución que sufrió su relación personal.

${ }^{14}$ Sobre la reforma del Consejo de Portugal y el intento de Lerma por ejercer un mayor control sobre este organismo véase LuXÁn MELÉndez, La revolución de 1640 en Portugal, págs. 156-194, especialmente el capítulo «El nuevo Consejo 1602-1606: los primeros pasos de la castellanización». Sobre el Consejo de Estado y la entrada en él de nuevos ministros leales a Lerma, véase R. GómEz RIVERo, «Lerma y el control de cargos», en José Antonio Escudero (coord.), Los validos (Madrid 2004), 80-119, págs. 82-93. 
el dinero con que se habían comprado ofensas de Dios» ${ }^{15}$. Sin embargo, cuando hubo que decidir cuánto dinero pondría cada uno de los estamentos del reino hasta completar la cantidad total surgieron los problemas. La Cámara de Lisboa se negó a aceptar la propuesta y todo se vino abajo. Sería muy interesante conocer los entresijos de esta cuestión.

4. Nuevos PRocuradores de los CRISTIANOS NuEVOS EN LA CORTE: Rodrigo de Andrade y Jorge Rodrigues Solís (1600-1603)

En vista de las dificultades que entrañaban las negociaciones, el caballero de la Orden de Cristo Martín Álvarez de Castro escribió al grupo de cristianos nuevos de Lisboa, para quienes hacía de procurador en la corte. Expuso cuáles eran los problemas aquí y pidió refuerzos. De tal manera, en 1600 llegaron a Madrid desde Lisboa Rodrigo de Andrade y Jorge Rodrigues Solís, «los hombres de la nación más ricos y más honrados» ${ }^{16}$. Lo primero que hicieron para desbloquear las negociaciones fue tratar de ganarse a Pedro Álvarez Pereira, lo que ahora resultaría más fácil, ya que por esos mismos días Cristóbal de Moura había sido despedido de la corte. Consiguieron ablandarle y que dejase de oponerse a las peticiones de los cristianos nuevos: Pedro Álvarez Pereira «se inclinó a hacerlo por contemplación de los dichos y por haber salido el negocio de las manos de éste [Martín Álvarez de Castro], con quien no estaba bien el dicho Pedro Álvarez» ${ }^{17}$.

Los nuevos procuradores Rodrigo de Andrade y Jorge Rodrigues Solís hicieron algunas otras gestiones para allanar el camino. Lo contó el propio Jorge Rodrigues Solís en el interrogatorio que le hicieron en febrero de 1607. Se decía natural de Lisboa y de 65 años de edad. Se había dedicado al comercio ultramarino, amasando una considerable fortuna. Era cristiano nuevo e hizo importantes esfuerzos en favor de los llamados «hombres de la Nación». Había llegado a la corte en el año de 1600, donde estableció contactos con los principales ministros del rey, incluido don Pedro Franqueza, con el objetivo de sacar adelante el pretendido perdón

${ }^{15}$ J. Lucio DE AzEVEdo, História dos cristãos novos portugueses (Lisboa 1975), págs. 155-157.

${ }^{16}$ AGS, Cámara de Castilla, leg. 2796, nº 9, fol. 137r.

${ }^{17}$ Ibid., fol. 137vto. 
general. Traían poder otorgado en Lisboa, por el cual se les permitía ofrecer un servicio al rey de 800.000 ducados ${ }^{18}$.

En cierta ocasión, explicaba, «andando en este negocio» le habló Pedro Álvarez Pereira. Le pidió que aceptara firmar un asiento con el rey por el que se comprometía a construir naves que hicieran el trayecto hasta la India. Su respuesta quedó escrita: «Señor, yo no trato de esas cosas, que sólo vengo a tratar del breve que pretende la nación, y si Su Majestad nos le alcanza yo haré lo que me mandéis». Como prueba de que las negociaciones avanzaban, Pedro Franqueza trajo una carta del rey a la Junta de Hacienda de Portugal en la que mostraba su predisposición a conceder la merced solicitada e interceder ante el papa para conseguir de Roma el perdón general. Pedro Franqueza entregó la carta a los procuradores de la «nación». Se aprovechó el momento para exigir a Jorge Rodrigues Solís que firmara con el rey el asiento de las naos de la India. «Señor, hasta ahora no está concedido el negocio que yo trato ni se puede deducir que lo está por una carta, pues Su Santidad podría no querer hacerlo». En la habitación estaban Jorge Rodrigues Solís, Pedro Álvarez Pereira y el confesor del rey. Este último apartó a Solís a un rincón y le dijo: «aquiétese, que con esta carta de Su Majestad luego se hará, que todo lo que Su Majestad pide concede el papa, y así bien podrá tomar asiento de fabricar las naos» ${ }^{19}$. Rodrigues Solís aceptó: durante nueve años, a contar desde 1602, construiría siete naves por año, obligándose a enviarlas a la India para traer de allí pimienta y otras mercaderías orientales.

Las sospechas de Jorge Rodrigues Solís se hicieron realidad. Se hizo una junta en la casa del nuevo Presidente del Consejo de Castilla, el conde de Miranda, en la que estuvo el propio duque de Lerma. Aquí se decidió pasar el negocio a la Junta de Hacienda de Portugal y finalmente se resolvió comunicar a Jorge Rodrigues Solís y Rodrigo de Andrade que «dilatasen su pretensión» y esperasen un mejor momento, con promesas de concederla entonces. Ellos pidieron una compensación a cambio. Querían que el rey al menos derogase «una provisión afrentosa contra la nación y les diese licencia para poder salir del reino libremente sin pedir licencia, y por esta merced hicieron de servicio 200.000 ducados, los cuales pagaron puntualísimamente» ${ }^{20}$.

\footnotetext{
${ }^{18}$ Ibid., fols. 143r-145vto.

${ }^{19}$ Ibid., fol. 143 r.

${ }^{20}$ Ibid., fol. 138vto.
} 
Fue de esta manera, en compensación por la espera al ansiado perdón general, como el rey Felipe III anuló la prohibición que impedía hasta entonces a los cristianos nuevos abandonar el reino de Portugal de forma definitiva. Desde 1601, año en el que se decretó la libertad, los cristianos nuevos podrían vender todos sus bienes, incluidos los raíces, y marchar con sus familias donde quisieran. En la carta firmada por el rey se dice que esta merced se hacía a petición de Jorge Rodrigues Solís y Rodrigo de Andrade, «procuradores dos Christaos novos dos ditos meus Reynos $e$ Senhorios». La carta-ley fechada y firmada en Madrid el 4 de abril de 1601 se complementó con otra fechada en Valladolid en julio de 1601 por la que se ampliaba la libertad concedida, señalando que los que marcharan del reino también podrían hacerlo con destino a la India, Brasil, Islas de San Tomé y Cabo Verde y a cualquier otro lugar de las conquistas de Portugal ${ }^{21}$.

Desde Lisboa, Cristóbal de Moura, ahora Virrey de Portugal, hacía todo lo posible por protestar ante tal medida, pero su aislamiento le restaba fuerzas. Pedro Álvarez Pereira, su antiguo amigo y fiel colaborador desde la secretaria del Consejo de Portugal y desde las juntas en las que participaba, había comenzado a distanciarse. Desde que Moura dejara la corte y marchara a Lisboa, los hombres de Lerma comenzaron a trabajar con el objetivo de romper la relación de amistad entre ambos. La idea era deshacer ese puente entre Lisboa y Madrid. Los dos eran conscientes de estas artimañas: "Quanto a o que V.M. me diz de nossa amistade -le escribía Moura-sempre entendí o mesmo que agora veio, por mais diabinhos que andarao de por meio, mas nunca forao parte para me fazer perder a fe, bem confesso que alguas vezes me achei fraco della, mas con o que V.M. me diz agora fico tam reteficado e firme como na quelle tempo» ${ }^{22}$. Pedro Álvarez Pereira se disculpaba por el retraso que sufrían las consultas y demás papeles que el virrey enviaba desde Lisboa al rey, y responsabilizaba de ello al propio duque de Lerma, que hacía que todo pasara por Pedro Franqueza, quien retenía todos los negocios en su poder.

Sin embargo, en poco tiempo la relación entre ambos fue deteriorándose. En octubre de 1601, año y medio después de su salida de la corte,

${ }^{21}$ AGS Estado leg. 2638, no 52. Leyes de 4/4/1601 y 31/7/1601.

${ }^{22}$ AHN Estado libro 81, fols. 59r-63r. Carta de Pedro Álvarez Pereira a don Cristóbal de Moura con la contestación de éste al margen (Madrid, 14/10/1600). 
Moura escribía a Pedro Álvarez Pereira quejándose de este hecho: «agora me affirmão pessoas de credito que Vuesa Merced não cumpre com a obrigação de nostra antigua amistade, e particularmente que não faz. bons officios em minhas cousas» ${ }^{23}$. Tristes palabras de quien fuera poco tiempo atrás el ministro más importante de la monarquía, ahora postergado y condenado al ostracismo. No obstante, siguió tratando de llamar a las puertas de la corte. Tras la medida de gracia de 1601 que dio libertad a los cristianos nuevos para salir de Portugal, Moura escribió al rey mostrándole su oposición. No se le hizo caso alguno y como consuelo sólo le quedó la queja amarga. La medida, decía, era producto del «engaño» de los cristianos nuevos, del mal consejo de ministros que poco o nada sabían en materias tan «grandes y nuevas», y de la negativa del monarca a escuchar a los ministros «cuerdos» que pedían mantener el camino trazado por los reyes anteriores ${ }^{24}$. La negociación con los cristianos nuevos fue, si duda, uno de los principales motivos de tensión entre la corte y el virrey, y lo que a la postre provocó la dimisión de éste de su cargo, producida en 1603.

\section{EL MODUS OPERANDI}

Estos detalles traídos aquí vienen al caso porque explican en buena medida cómo fueron las negociaciones entre los procuradores de los cristianos nuevos y los ministros del rey entre 1598 y 1606. Pedro Franqueza, verdadero muñidor de estas conversaciones, aprovechó la ocasión para obtener beneficios y condiciones ventajosas de los hombres de negocios lisboetas: beneficios para el rey, pero también para sí mismo. Desde sus cargos en la Junta de Hacienda de Castilla, en la Junta de Hacienda de Portugal y, desde 1603, en la Junta de Desempeño General del Reino trató con los hombres de negocios desde una posición aventajada. Él también era quien conducía las negociaciones con los procuradores de los cristianos nuevos en la corte, de manera personal o por persona interpuesta. Y gracias a su lugar privilegiado en la corte y al poder que acumuló en sus manos presionó a unos y otros para optimizar los tratos. Así, por

${ }^{23}$ Ibid., fol. 67r. Carta del virrey don Cristóbal de Moura a Pedro Álvarez Pereira (Lisboa, 22/10/1601).

${ }^{24}$ Ibid., fols. 69r-70vto. Así lo explicaba don Cristóbal de Moura a su antiguo colaborador, el secretario de Felipe II, Juan de Idiáquez, en una larga carta fechada en Lisboa a 23/7/1601, en la que le pedía además que procurara que sus cartas fueran vistas por el rey. 
ejemplo, cuando en 1604 llegó a la corte el nuevo procurador Afonso Gomes para continuar con las negociaciones, Pedro Franqueza volvió a aprovechar la ocasión: «le hizo tomar los daños y costas de la pimienta, la cual al presente tiene este testigo [Afonso Gomes], en la cual perdió luego 80.000 ducados por alcanzar el beneficio que pretendía la nación y Franqueza tenía prometido; y por tomar éste [el asiento de] la pimienta ganó el rey 140.000 ducados» ${ }^{25}$.

Los miembros de la Junta de Hacienda de Portugal en la corte, Pedro Franqueza, Pedro Álvarez Pereira, el confesor regio, Alonso Ramírez de Prado, presionaban a los procuradores de los cristianos nuevos, quienes intentando hacer progresar la negociación de sus pretensiones acababan firmando asientos con la Corona en términos muy ventajosos para ésta y, por el contrario, ruinosos para ellos. Pedro Franqueza dirigía las operaciones y Pedro Álvarez Pereira, que conocía bien a sus paisanos, los hombres de negocios lisboetas, establecía los puentes entre ellos y la junta. Otras veces, Pedro Franqueza se valía de personas ajenas a la junta, como hizo en tantas ocasiones con el mencionado Martín Álvarez de Castro, lo que le permitía mantener la discreción necesaria en asuntos turbios que luego se conocieron.

Las promesas y gestos de estos ministros se vendían a buen precio. Su cercanía al valido era lo que marcaba su alta cotización en la corte. Así, declaraba Afonso Gomes que en cierta ocasión Pedro Álvarez Pereira le pidió 10.000 ducados prestados, sabiendo ambos que ninguno haría nada por su devolución, como en verdad ocurrió. Lo que sacó en provecho Pedro Franqueza, entre dinero, joyas y otros beneficios, ascendía a decenas de miles de ducados. Ambos terminaron presos y juzgados por corrupción. Como dos buenos ejemplares de la picaresca, en este caso nada había de ficción, llegaron incluso a disputarse el botín que sacaron de estas gentes buscadoras de mercedes regias en una corte convertida en mercado de favores.

Las dificultades y la demora en las negociaciones no hacían más que aumentar los beneficios particulares de estos ministros. Rodrigo de Andrade y Jorge Rodrigues Solís consiguieron poca cosa tras sus años de gestiones en Madrid y Valladolid entre 1600 y 1603. Salieron desplumados. Rodrigues Solís volvió a Lisboa con altas sumas pendientes por cobrar del rey; Rodrigo de Andrade marchó a Roma, para procurar librar a su mujer, presa en la Inquisición portuguesa. Llevaba en su mano una

\footnotetext{
${ }^{25}$ AGS Cámara de Castilla leg. 2796, nº 9, fol. 147vto.
} 
carta que Felipe III dirigía al papa apoyando la solicitud del breve necesario para el perdón general. Tiempo después, la Inquisición de Portugal arremetió contra él. Escribieron desde Lisboa al rey protestando por las gestiones que Rodrigo Andrade hacía ante el papa para favorecer la excarcelación de su mujer, ya que con ello estaba cuestionando la rectitud en el procedimiento inquisitorial y ocasionando un grave daño a la reputación de la institución ${ }^{26}$.

6. El procurador Gerónimo Castaño y sus gestiones entre 1603 Y 1604

Fuera de la corte Jorge Rodrigues Solís y Rodrigo de Andrade, Gerónimo Castaño se hizo cargo de las negociaciones durante el breve periodo que va de 1603 a 1604. Traía poder de los cristianos nuevos de Lisboa. Él fue quien negoció el servicio que se firmaría con el rey a cambio del perdón general. La suma de este servicio ascendía a 1.700 .000 ducados, más lo que se habría de distribuir entre los ministros del rey en concepto de comisiones. Gerónimo Castaño era amigo de los principales ministros portugueses en la corte. Entre ellos estaba Pedro Álvarez Pereira, el ministro de la Junta de Hacienda de Portugal y del Consejo de Portugal. También era amigo del cristiano nuevo Hector Mendes «el rico».

Pedro Franqueza hizo todo lo posible para ganarse al nuevo procurador. Le demostró que él era quien tenía en su mano todo el negocio del perdón general y que por tanto él era quien debía recibir las cuantiosas comisiones a distribuir. Le explicó que en lo tocante a este negocio no debía fiarse de ningún otro ministro; tampoco de Pedro Álvarez Pereira. Para asegurase de esto último, alimentó la discordia entre ambos amigos y, en breve, lo que era amistad acabaría convirtiéndose en odio declarado.

\section{LAS NEGOCIACIONES DEL PROCURAdOR AfONSO GOMES}

En 1604 llegó a la corte en Valladolid Afonso Gomes, el nuevo procurador, con poder de algunos cristianos nuevos para distribuir entre los ministros albricias y gratificaciones, cifradas en miles de ducados. En

${ }^{26}$ AGS Estado leg. 435 expte. 24. 
Lisboa no se fiaban de Gerónimo Castaño para este cometido. Dudaban de su buen criterio, por ser «hombre trabajoso y de mala fama», además de gran «pleiteísta». Por el contrario, Afonso Gomes, vecino y natural de Lisboa, viejo de casi setenta años, se consideraba «fiel y hombre honrado» para manejar a su libre arbitrio el dinero de los cristianos nuevos de Lisboa. Garantizaba un buen reparto de las gratificaciones.

Cuando Afonso Gomes llegó a la corte, lo primero que hizo Gerónimo Castaño fue mostrarle quién era el ministro clave en las negociaciones con la Corona. Le llevó a casa de Franqueza y éste le explicó allí «lo mucho que había hecho en traer este negocio a efecto» ${ }^{27}$. Luego les confió un secreto. El breve del papa autorizando el perdón general ya había llegado a la corte: «ya ha venido el breve, calladlo y no lo digáis». Acto seguido visitaron a Pedro Álvarez Pereira, quien hasta hace poco había sido en la corte el puente obligado entre los cristianos nuevos y el rey. Ahora estaba siendo marginado. Cuando le preguntaron por el estado de sus negocios, Pedro Álvarez Pereira les contestó que el breve del papa todavía estaba por llegar. Gerónimo Castaño, después, le dijo a Afonso Gomes: «veis aquí lo que os digo si es mejor negociar por Villalonga; tenéis el breve en las manos y Pedro Álvarez nos dice que presto vendrá concluido todo esto» ${ }^{28}$.

Ahora sólo faltaba que Felipe III autorizara la publicación en sus reinos del mencionado perdón general haciéndolo así efectivo. En otra reunión, Pedro Franqueza explicó a Afonso Gomes las muchas dificultades que existían para que el rey publicara el breve pontificio. Lo que más les preocupaba, decía, era el escándalo que causaría la noticia, como en efecto ocurrió. En Portugal, la oposición a esta merced era extraordinariamente fuerte ${ }^{29}$. Cuando tiempo atrás se tuvo noticia en aquel reino de la solicitud enviada por el rey a Roma, se organizó la estrategia para tratar de abortar la iniciativa. La nobleza y el clero portugués se movilizaron. A la cabeza de la oposición estaban las principales dignidades eclesiásticas de aquel reino: los arzobispos de Lisboa, Braga y Évora. Escribieron a Roma «suplicando que hasta ser oídos de Su Majestad se dilatase la concesión del dicho breve, como en efecto se dilató» ${ }^{30}$. Posteriormente los

\footnotetext{
${ }^{27}$ AGS Cámara de Castilla leg. 2796, nº 9, fol. 139r.

${ }^{28}$ Ibid., fol. 147 vto.

29 A. Borges Coelho, Política, Dinheiro e Fé (Lisboa 2001), págs. 131-134.

${ }^{30}$ AGS Cámara de Castilla leg. 2796, nº 9, fol. 138r.
} 
tres arzobispos viajaron hasta Valladolid y hablaron con el monarca. Nada consiguieron. Pedro Franqueza y el confesor regio se habían encargado de eliminar los problemas que pudieran asaltar la conciencia del rey. Para ello se valieron del Padre Cicilia, quien reunió los pareceres favorables a aquella merced dictados por prestigiosos teólogos de las universidades españolas y también por doctos padres de la Compañía de Jesús.

Con todas estas razones, Pedro Franqueza convenció a Afonso Gomes de lo necesario que era elevar el servicio a más del doble de lo previsto por los cristianos nuevos lisboetas. Cuando le llevó a ver al duque de Lerma, el negocio se cerró en 1.700.000 ducados. Por su parte, don Pedro Franqueza recibió la mayor cantidad de las comisiones repartidas. Afonso Gomes explicó con detalle cómo le había pagado a Franqueza las gratificaciones. En total le dio alrededor de 86.000 ducados, repartidos en varias entregas. En una primera ocasión le dio en su propia mano 6.000 escudos de oro, y por seis veces 4.000 ducados cada una, todos en oro y sólo 2.000 en plata. A través de Gerónimo Castaño le dio a la condesa de Villalonga una cadena de diamantes que le había costado 5.000 ducados, que éste le puso en el cuello como muestra de gratitud a su marido. En otra ocasión envió a la condesa una caja de oro llena de azúcar y otras golosinas. No es extraño que Pedro Franqueza le dispensara un trato tan cordial: «Señor Afonso Gomes, yo soy su amigo -le dijo- y todo cuanto hubiere en esta casa está a su servicio, que no ha venido aquí portugués como Vuestra Merced». No era extraño. Calculaba Afonso Gomes que había distribuido en dinero y joyas más de 250.000 ducados a diferentes personas, «que no se acuerda qué tantos, pero respectivamente Franqueza llevó la sustancia». Incluso, entre los criados de Franqueza repartió en diversas ocasiones más de 600 ducados ${ }^{31}$.

Conforme le iban interrogando a Afonso Gomes a principios de 1607, salían a la luz nuevas entregas de dinero y regalos. Explicó también que hizo algunos giros a favor de Pedro Franqueza sobre la banca de los Spínola por valor de 40.000 escudos, 20.000 escudos... También reconocía que en otras ocasiones le ofreció dinero pero éste no quiso cogerlo: «el dicho conde dijo que la nación le había dado mucho, que no quería más» ${ }^{32}$. El sobrino de Afonso Gomes, don Jacome de Olivares, natural y

\footnotetext{
${ }^{31}$ Ibid., fols. 148 r-vto.

32 Ibid.
} 
vecino de Lisboa, vino a la corte para ayudar en esta tarea a su tío, viejo y enfermo. Solía visitar a Pedro Franqueza y éste le recibía «muy bien y le hacía mucha merced». Acudía habitualmente con grandes sumas de dinero en oro, que entregaba en mano del propio Franqueza. Recordaba que le dio 40.000 ducados por el trabajo e interés que puso para que $\mathrm{Su}$ Santidad enviase el breve del perdón general.

Afonso Gomes solicitó del rey una cédula para que el total del dinero distribuido entre los distintos ministros se pudiera recuperar haciendo un repartimiento entre los cristianos nuevos de Portugal. Así, a los 1.700.000 ducados del servicio comprometido con el rey habría que sumar otros 175.000 ducados en concepto de «despesas». Llama la atención que esta distribución de dádivas, albricias, regalos y comisiones contase con el amparo regio y que el rey pusiera su firma en una cédula que reconocía una práctica que se confundía con la corrupción ${ }^{33}$.

\section{OPOSICIÓN AL SERVICIO; OPOSICIÓN AL PERDÓN GENERAL}

El servicio pactado entre los cristianos nuevos y los ministros de Felipe III alcanzó una suma no prevista en un principio. El poder que trajeron en 1600 los procuradores Jorge Rodrigues Solís y Rodrigo de Andrade mejoraba la cantidad ofrecida por el antecesor en el cargo, Martín Álvarez de Castro, y fijaba el servicio en 800.000 ducados. Geronimo Castaño en 1603 lo elevó hasta 1.700 .000 ducados, más las comisiones, alcanzando la cifra de 2.000.000 de ducados. En 1604, el nuevo procurador Afonso Gomes aceptó esta cantidad como buena. Todos ellos estaban en permanente contacto con Hector Mendes «el rico», quien desde Lisboa lideraba al grupo de cristianos nuevos que había promovido la iniciativa en 1598. Por ello, cabe pensar que Hector Mendes no estaba al margen de este punto fundamental.

Una vez se tuvo noticia sobre los términos del servicio ofrecido al rey, cuál era la cantidad total a pagar y quiénes eran los que estaban comprendidos en el repartimiento que se haría para recaudarlo, aparecieron numerosas protestas. Afonso Gomes, para compensar el aumento del servicio hasta los dos millones de ducados, había tenido que solicitar que la recau-

${ }^{33}$ La cédula del rey aparece en ibid., fols. 156r-vto. Sobre el fenómeno de la corrupción véanse las interesantes páginas de Feros, El Duque de Lerma, págs. 304-335. 
dación se hiciera entre todos los cristianos nuevos portugueses, también entre aquellos que vivían ya en España. Lo trató con Pedro Franqueza, que aceptó la propuesta ${ }^{34}$. De esta manera, para llevar a cabo la recaudación del servicio se establecieron cinco grupos: los cristianos nuevos de Lisboa pagarían algo menos de un tercio del total; los del resto del reino de Portugal, divididos en 25 comarcas, pagarían casi la mitad del servicio. La diferencia se repartiría entre los cristianos nuevos de Castilla por un lado, los de las conquistas de Portugal, incluido Brasil por otro, y por último, entre los cristianos nuevos que habitaban en la India. Para el cobro del servicio se organizó una junta o tribunal en Lisboa presidida por don Constantino de Melo y que funcionó entre 1605 y $161{ }^{35}$.

En la propia corte se alzaron voces de protesta entre gentes de condición cristiano nueva. Protestaron los cristianos nuevos que vivían en Castilla, quienes no aceptaron que se les incluyera entre los contribuyentes a este servicio, señal inequívoca de que se sentían fuera y libres del colectivo portugués: «Habiéndolo entendido algunos de los que vivían en Castilla y considerando el agravio que les hacían, ansí por ser ellos buenos christianos como por no ser comprehendidos en el breve sino como naturales y moradores en Portugal y en la Europa, acudieron diversas veces y diversas personas a hablar al dicho Franqueza y a Ramírez de Prado». Uno de los que habló con Pedro Franqueza para manifestarle su desacuerdo fue Leonel de Quadros, comerciante vecino de Sevilla. También fue a hablarle Pedro Gomes Reynel, poderoso hombre de negocios, que tuvo un trato muy estrecho con Pedro Franqueza por esos mismos días. En presencia de éste, Gomes Reynel acusó a «Afonso Gomes del agravio que hacía a mucha gente principal que estaba mezclada con alguna parte de la nación y raza». Pedro Franqueza les aconsejó que evitasen acudir a la justicia ordinaria y prometió ayudarles. En El Escorial se dieron peticiones escritas sobre el caso, que se vieron en una junta sin resultado. Pedro Gomes Reynel arremetía contra Afonso Gomes: «de todo esto tiene la culpa el dicho Afonso Gomes, y Franqueza le ayudaba, a lo que este testigo presume por lo que le había dado y esperaba reci-

${ }^{34}$ AGS Cámara de Castilla leg. 2796, nº 9, fol. 153vto.

${ }^{35}$ AGS Secretarias Provinciales libro 1557, «Libro de cuentas del Perdón General». Sobre los miembros que componían esta junta fols. 53r-vto. Ya utilizó esta documentación A. Marques de Almeida, «O Perdão Geral de 1605», en Primeiras Jornadas de História Moderna (Lisboa 1986), vol. II, págs. 885-898, donde analiza los pormenores en el cobro del servicio ofrecido por los cristianos nuevos. 
bir; y Ramírez de Prado ansimismo fomentaba esto por ser de la Junta y parcialidad del dicho Franqueza, aunque no sabe que Ramírez de Prado hubiese recibido dinero ni otra cosa» ${ }^{36}$.

El perdón general provocó un profundo descontento entre los cristianos nuevos. No sólo entre los que habitaban en Castilla. Especialmente, hubo fuertes disensiones entre los propios cristianos nuevos que vivían en Portugal, las cuales se manifestaron de muy diversa manera. Fueron muy numerosos los que procuraron evadirse del pago del repartimiento que les tocaba. Hubo agresiones contra quienes tenían que ejecutar el cobro, lo que obligó a la Corona a intervenir en su defensa castigando a los revoltosos ${ }^{37}$. Otros, los más pudientes, solicitaron al rey que se les eximiera del pago, arguyendo no tener apenas ya lazos con el colectivo cristiano nuevo, y sí, por el contrario, méritos suficientes como para ser considerados al margen de este grupo afrentado. Así, por ejemplo, Duarte Ximenes y su mujer Isabel Baptista obtuvieron un decreto del rey firmado en 1607 por el cual se les eximía de la contribución al servicio. Llegaron a ser tantas las peticiones de particulares que el rey acabó por decretar que no se hicieran más solicitudes de exención ${ }^{38}$.

Entre el grupo de cristianos nuevos lisboetas la ruptura interna fue más profunda. Más de medio centenar de destacados hombres de negocios lisboetas enviaron un memorial al rey rechazando el perdón general y, en consecuencia, el servicio que se les obligaba a hacer como contrapartida. Mostraban, además, su desacuerdo con aquellos que desde Lisboa habían promovido las negociaciones en Madrid. Negaban que Afonso Gomes fuera su procurador en la corte y no le reconocían como su representante. Representaba, decían, sólo a unos pocos: «Afonso Gomes, bajo pretexto de hacer procuración, que alcanzó de algunas personas particulares de la gente de la nación de dicho reino, que fueron los de menos suerte y cualidad, y muy interesadas por tener sus hermanos, mujeres y parientes presos en las cárceles de la Santa Inquisición, y ver sus haciendas y personas muy arriesgadas...». En resumen, Afonso Gomes no tenía autoridad para hablar en «nombre del común de la dicha gente» ${ }^{39}$.

${ }^{36}$ AGS Cámara de Castilla leg. 2796, nº 9, fols. 153vto-154r.

${ }^{37}$ Lucio de AzEvedo, História dos cristãos novos portugueses, págs. 163-164.

${ }^{38}$ Biblioteca de Ajuda (Lisboa), 51-VIII-8, $n^{\circ} 2$.

39 ANTT, Conselho Geral Santo Oficio, liv. 314, fol. 51r. Memorial fechado en Lisboa, 31/10/1605. 
Tampoco estaban de acuerdo con el tipo de medidas pedidas al rey: «nuevas libertades y cosas llenas de escándalo, muy afrentosas y perjudiciales para la honra, limpieza y buen procedimiento de la gente principal... viniendo a ser en efecto lo que se pide casi libertad de conciencia». Por ello, durante las negociaciones, estos individuos se habían movilizado para protestar delante de Su Majestad, del Virrey y del Tribunal del Santo Oficio. Al rey le pidieron que no aceptase procurador ni petición hecha «en nombre del común». Se negaron a firmar el poder dado a los procuradores enviados a la corte. La razón de fondo, y esto merece ser resaltado, era que los cristianos nuevos, a quienes se suele ver como una comunidad bajo este nombre, una nación en sí misma, no constituían en realidad tal comunidad, a decir por muchos de ellos: «que los que se dicen que traen su descendencia de dicha gente, no tienen gobierno, ni república separada, antes viven en un cuerpo místico con los demás cristianos viejos del reino». Por lo tanto, nadie podía asumir legítimamente la representación de estas gentes, ni negociar en su nombre y adoptar compromisos que les incluyera. No, sin el consentimiento expreso de cada uno, y ellos en concreto se habían negado en ocasiones anteriores a darlo ${ }^{40}$.

Este es un hecho fundamental que hoy se suele olvidar por muchos de quienes se acercan al estudio de este problema. En el reinado de Felipe III, los ministros que condujeron las negociaciones aquí analizadas pasaron por alto esta circunstancia, lo que se explica por su urgente necesidad de conseguir recursos financieros para el maltrecho erario. Por ello, reconocieron a estos procuradores como representantes legales de la nación, asumiendo que ésta formaba un cuerpo diferenciado del resto. Detrás de esta visión había un interés crematístico, que era el que movía a los ministros de la Junta de Hacienda de Portugal y del Desempeño General del Reino.

Los promotores de las negociaciones en Lisboa, cristianos nuevos pertenecientes al mundo de los negocios, asumieron un liderato que no les correspondía, que no se aceptó por muchos a decir por las protestas y por la negativa a cumplir con los compromisos firmados en la corte. Se había asumido el liderato con la intención de negociar en nombre de «un

${ }^{40}$ Ibid. Traté sobre este problema conceptual referido a la identidad de estas gentes en mi «De la identidad, emigración e integración de los cristaos novos en la época filipina», Inquisição Portuguesa: Tempo, Razão e Circunstancia, L. F. Barreto, J. A. Mourão, A. C. da Costa e J. E. Franco (coord.) (Lisboa-São Paulo 2006), págs 139-164. 
común» que ni era común ni se sentía representado. Los autoproclamados líderes de la nación aprovecharon las circunstancias de aquel momento crítico y se erigieron en representantes de todos los cristianos nuevos. Fue una iniciativa arriesgada y con algunas señales de precipitación, lo que provocó su rápido fracaso, entre otras cosas, por las tensiones que generó entre los propios cristianos nuevos. «Personas particulares», que sólo se representan así mismos, decían los firmantes del memorial que venimos aludiendo, más de medio centenar de cristianos nuevos lisboetas, cuyas firmas aparecen en dos folios al final del mencionado documento ${ }^{41}$.

Los autores de este memorial de protesta contra las pretensiones de los negociadores en la corte se autocalificaban como gente honrada y notable: «son la sustancia de los hombres de negocios deste reyno, de más posibilidad, limpieza y procedimiento, y con quien se corrió siempre en todos los negocios y ocasiones que se ofrecieron al servicio de Su Majestad y de los Señores Reyes sus antepasados, y algunos de ellos fidalgos y hombres nobles y reputados». Se sentían integrados y parte de la sociedad católica. Por ello decían no necesitar medidas novedosas, las cuales sólo les provocaba agravios innecesarios. El repartimiento del servicio comprometido con el rey traía consigo que «gente apasionada [...] desenterrase los antepasados» de mucha otra gente honrada: fidalgos, letrados, caballeros de órdenes militares y otros criados del rey, emparentados con los linajes más ilustres del reino. La finalidad era incluirlos como contribuyentes, lo que provocaba una afrenta insoportable para quienes trataban de hacer olvidar. «Injustamente fintados pellos lanzadores», sufrieron una grave vejación. Los recaudadores del servicio les incluían en el repartimiento sin razón: unas veces por ser cristianos viejos por naturaleza, otras veces por la antigüedad de sus antepasados y por los privilegios que gozaban, por tener sentencias anteriores en su favor, por estar apartados de aquellas gentes, por haberse mezclado con los cristianos viejos... ${ }^{42}$.

De tal manera, los firmantes del memorial dieron un poder a quienes consideraban sus legítimos procuradores: Rui Lopes de Évora, Álvarez Gomes de Elvas, vecinos ambos de Lisboa, y Antonio Gomes de Elvas, vecino de Valladolid, donde ahora estaba la corte ${ }^{43}$. Se les encomendó

${ }^{41}$ ANTT, Conselho Geral Santo Oficio, liv. 314, fols. 54r-vto.

${ }^{42}$ Ibid., fol. 52r-53r.

${ }^{43}$ Biblioteca de Ajuda (Lisboa), 51-VIII-6, $\mathrm{n}^{\circ}$ 818. Sobre el primero de estos hombres: «Pretensión de los hijos e hijas de Rui Lopes de Évora de excusarse de la contribu- 
la tarea de acudir ante los ministros del rey y ante los principales tribunales, en particular ante el Consejo Real de Castilla, para protestar y rechazar los acuerdos tomados por Afonso Gomes o por cualquier otro procurador.

Además de la queja de estos hombres, tampoco hubo acuerdos entre los que en Lisboa habían dado poder a Afonso Gomes. La cantidad del servicio firmado, 1.700.000 ducados, les resultaba excesivo. Martín Álvarez de Castro, el primero de los procuradores, llegado a Madrid en 1598, fue comisionado para que protestase dicha cantidad. En sus declaraciones durante el interrogatorio de 1607 recordaba que «en Lisboa contradijeron todos los de la nación la cantidad de dinero» y le escribieron una carta pidiéndole que lo rechazara. Le pidieron que hablara a los ministros del rey, como hizo, y les dijera que Afonso Gomes «había prometido lo que ellos no podían cumplir», y que lo había hecho para que soltaran a un hermano que tenía preso en las cárceles de la Inquisición ${ }^{44}$.

La unidad de acción de los cristianos nuevos lisboetas, si alguna vez existió, estaba rota. Las acusaciones contra los principales artífices en las negociaciones decían que actuaban en interés propio. En el memorial que venimos comentando se acusaba a los promotores del perdón general de hacerlo por motivos oscuros. Decían que sus hermanos, mujeres y parientes estaban presos en la Inquisición y que sus haciendas corrían un alto riesgo de ser confiscadas. Es difícil saber qué hay detrás de este juicio de intenciones, por otra parte muy repetido entonces por los detractores de las negociaciones y por quienes se oponían a estas medidas de gracia. Rodrigo de Andrade tenía a su mujer, Ana Milán, presa en el Santo Oficio y su viaje a Roma, se dijo, tenía como objeto procurar desde allí su excarcelación. El propio Afonso Gomes tenía a su hermano Juan Rodrígues preso en la Inquisición de Portugal. Y Hector Mendes «el rico», principal promotor de las negociaciones entre 1598 y 1606, también tenía familia procesada por el Santo Oficio. Él mismo estaba siendo investigado por la Inquisición portuguesa en los años en los que se desarrollaban las negociaciones. Las diligencias abiertas fueron suspendidas sin que se

ción al pago de los 200.000 cruzados con que la gente de la nación sirvió por la licencia que se les dio para poder salir libremente del reino de Portugal (12-6-1607)».

${ }^{44}$ AGS Cámara de Castilla leg. 2796, nº 9, fol. 139vto. 
sepa cuál fue la razón de ello ${ }^{45}$. No extraña que ante el giro que dieron las cosas hacia 1606 y su difícil situación personal, Hector Mendes acabara por pensar que lo mejor sería abandonar Portugal ${ }^{46}$.

Las acusaciones tenían cierta consistencia, a tenor del sentido último de las peticiones realizadas al rey. La libertad para salir de Portugal decretada en 1601, el perdón general, la eliminación de la confiscación de bienes a los sentenciados por el Santo Oficio, ciertas garantías procesales para los reos de la Inquisición; todas estas medidas iban en una misma dirección. Lo que se pretendía con ellas era poner a salvo las haciendas y negocios de los cristianos nuevos que más tenían que perder ante un posible tropiezo con la Inquisición. Tampoco se puede descartar que los ministros de la Inquisición de Portugal hubieran incoado aquellos procesos contra los familiares de los procuradores o contra alguno de los más destacados líderes del grupo como fórmula de presión, represalia o amenaza con la que obstaculizar el proceso negociador.

Otra de las consecuencias del perdón general fue la conmoción social que causó en Portugal y la reacciones violentas que allí tuvieron lugar cuando fue publicado en enero de 1605 . Hubo tumultos en Lisboa cuando se sacó de las cárceles a los reos presos en ellas. En Coimbra alcanzaron una mayor magnitud y en otras localidades del reino también se repitieron episodios de triste recuerdo. El perdón benefició a varios centenares de procesados, casi medio millar en Portugal ${ }^{47}$. En España afectó a muchos menos: «Hay tan pocos cristianos nuevos portugueses presos en las Inquisiciones de estos reinos», escribía el Inquisidor General de España a su homólogo en Portugal ${ }^{48}$. No obstante, los procuradores de los cristianos nuevos tuvieron que esforzarse para detener la celebración del auto de fe previsto en Sevilla para primeros de noviembre del año de 1604, cuando todavía no se había hecho público el perdón general. Afonso Gomes recibió una carta desde Sevilla en la que un tal Gregorio Díaz de Luna le daba aviso de haberse anunciado ya; hizo gestiones

${ }^{45}$ Sobre el procedimiento abierto contra Hector Mendes nos informa C. STUCZINSKY, «New Christian Political leadership in times of crisis. The Pardon negotiations of 1605» (en prensa). Agradezco al autor que me permitiera la lectura de su trabajo.

${ }^{46}$ Biblioteca de Ajuda (Lisboa), 51-VIII-16, $\mathrm{n}^{\circ}$ 13, fol. 24. «Sobre nao convir dar-se a licença que pede Heitor Mendes para se ausentar do Reino, que teni dos irmaos declarados judeus: um em Veneza, outro em Salónica» (2/8/1612).

${ }^{47}$ Borges Coelho, Política, Dinheiro e Fé, pág. 133.

${ }^{48}$ ANTT Conselho geral Sato. Oficio Liv. 443, fols. 3r-vto. 
en la corte y de forma inmediata escribió al rey solicitando que se suspendiera. Así se lo comunicó Su Majestad al Inquisidor General de España y el auto fue suspendido. Esta era la fuerza de aquellas gentes, lo que les granjeó una enorme aversión entre los naturales ${ }^{49}$.

\section{LAS NEGOCIACIONES ENTRE 1605 Y 1607}

Una vez conseguido el perdón general en 1605, el procurador Afonso Gomes continuó con las negociaciones en la corte. Su interlocutor seguía siendo don Pedro Franqueza. Los objetivos de Afonso Gomes fueron tres: conseguir un nuevo perdón general, eliminación de la confiscación de bienes a los penitenciados por el Santo Tribunal y que en los procesos se notificase a los reos quiénes eran los testigos que deponían contra ellos ${ }^{50}$.

Sobre el nuevo perdón general negociado por Afonso Gomes nos informa Martín Álvarez de Castro. Explicaba este hombre cómo tras la publicación del perdón general en 1605 la Inquisición portuguesa había intensificado la represión: «que ahora nuevamente han hecho en Portugal por la Inquisición muchas prisiones en que entra alguna gente granada y de consideración por lo cual de allá han escrito a este declarante el miserable estado en que vuelven a estar». Afonso Gomes le había dicho en muchas ocasiones «la forzosa y precisa necesidad que el Reyno de Portugal tiene de otro perdón nuevamente concedido». Para ello, decía, se obligarían las personas más granadas de la nación, socorriendo al rey con la cantidad que fijase, la cual entregarían de un solo golpe en Flandes, donde había tanta necesidad de efectivos. Afonso Gomes había recurrido a Martín Álvarez de Castro para este fin, sabiendo la estrecha relación que tenía con Pedro Franqueza e, incluso, con el duque de Lerma.

En 1606 se negoció también la posibilidad de introducir algunos cambios en el procedimiento inquisitorial. Para ello, Afonso Gomes pidió a Martín Álvarez de Castro que intercediera e hiciera valer su amistad con Pedro Franqueza. Lo hizo, y en cierta ocasión «trató con el Conde de Villalonga [Franqueza] y el Licenciado Ramírez de Prado que no se confiscasen los bienes a los de la Nación y se les diesen los nombres de los testigos» que

49 AGS Cámara de Castilla leg. 2796, nº 9, fol. 150r.

${ }^{50}$ Declaraciones de Martín Álvarez de Castro, AGS Cámara de Castilla leg. 2796, nº 9, fols. 140r-vto. 
contra ellos hubieran testificado. Como contrapartida a estas mercedes estaban dispuestos a ser generosos. Por el negocio de los nombres de los testigos darían 100.000 ducados perpetuos situados sobre la gente de la nación. Por la exención de la pena de confiscación de bienes a los culpados de judaísmo, que pedían estuviera vigente durante un plazo de 20 años, darían al rey otros 200.000 ducados: cien mil dados y otros cien mil prestados sin interés. Martín Álvarez de Castro habló también de estas pretensiones al confesor regio. Lo hacía, dijo, llevado del deseo de servir al rey, «porque no entiende en otra cosa más que en buscar dineros para Su Majestad, y todo lo que se le ofrece propone a la Junta, y ella elige lo que conviene al servicio de Su Majestad» ${ }^{51}$.

El propio Afonso Gomes habló con Pedro Franqueza sobre este asunto. Fue pocos meses antes de que le apresaran acusado de varios ciento de cargos. Afonso Gomes aceptó, incluso, tomar el asiento de la pimienta, a pesar de las grandes pérdidas que le ocasionaría. Le ofreció también algunas gratificaciones si agilizaba el negocio. Afonso Gomes se comprometió con Pedro Franqueza a entregar en octubre de 1606 cien mil ducados y otros cien mil prestados, pidiendo a cambio que le dejasen meter en Castilla 3.000 quintales de pimienta, «para llegar el dinero con mayor brevedad» ${ }^{52}$. El cargo número 397 que aparece en la sentencia dictada contra Pedro Franqueza tras su largo proceso especifica este asunto. Se dice que éste se aprovechó de su cargo y autoridad para favorecer y tramitar las peticiones de los procuradores a cambio de los grandes ofrecimientos y promesas que le hicieron. Grave exceso para un ministro, por lo descabellado de las pretensiones y por lo turbio en el proceder de un criado del rey ${ }^{53}$. Cuando se estudió la petición en la Junta de Hacienda de Portugal, estando ya fuera de ella los ministros Pedro Franqueza, Alonso Ramírez de Prado y Pedro Álvarez Pereira, por sus respectivas prisiones, se desaconsejaron tales medidas con palabras graves: «sobre los ofrecimientos... que hace Afonso Gomes en nombre y con poder general de la nación hebrea... pareció a la Junta que la persona que tiene atrevimiento para representar a V.Magd. semejantes propuestas debe ser castigado y echado desta Corte» ${ }^{54}$.

${ }^{51}$ Ibid., fol. 141 vto.

${ }^{52}$ Ibid., fol. 150 r.

${ }^{53}$ AGS Cámara de Castilla, leg. 2796bis, n 15, fols. 219r-220r., cargos n 395, 396, 397.

${ }^{54}$ AGS SP Libro 1466, fols. 66r.vto. y 74r.-76vto. El documento lo ha transcrito Martín Gutiérrez, La Junta de Hacienda de Portugal, págs. 513-516: «Consulta de la 
La grave crisis política que vivió el régimen del duque de Lerma entre 1606 y 1607 frustró estas últimas negociaciones que se quedaron sin cerrar. El principal conductor de las negociaciones, el catalán Pedro Franqueza, acabó preso en la cárcel acusado de cientos de delitos, entre ellos haberse cohechado con los hombres de negocios portugueses. Murió en prisión en 1614. Sus compañeros en el gobierno, Alonso Ramírez de Prado y Pedro Álvarez Pereyra corrieron parecida suerte. Con ellos, y en particular con Pedro Franqueza, concluyó un periodo de cambio radical en la política referida a los cristianos nuevos. Como para otras cosas, tal fue el caso del problema morisco, se produjo un giro extraordinario que de alguna manera sirvió para exorcizar males mayores en la monarquía.

A finales de 1607 el rey daba orden para que Afonso Gomes, su sobrino Jacome de Olivares y Martín Álvarez de Castro fueran expulsados de la corte y no se admitiera en ella nuevos procuradores de la gente de la nación ${ }^{55}$. En diciembre de 1607 Felipe III impuso silencio perpetuo sobre las peticiones tocantes a los cambios en el procedimiento inquisitorial. Desde esas fechas se comenzó a trabajar desde las instancias institucionales ordinarias, lejos ya de las juntas anteriores. El objetivo ahora era la eliminación de todo lo hecho en esta materia desde 1598. En 1610 se revocaría la libertad decretada en 1601 por la que los cristianos nuevos podían abandonar Portugal sin licencia. Después vendrían nuevas medidas adversas a estas gentes.

Junta de hacienda de Portugal dando cuenta a Su Majestad de lo que se ha hecho sobre los papeles que presentó Martín Álvarez de Castro» (17?/2/1607).

${ }_{55}$ Biblioteca de Ajuda (lisboa), 51-VIII-17, n 111, fol. 149r. 


\section{RESUMEN}

En la larga evolución del problema judeoconverso en la historia de España y Portugal, la política desarrollada por el rey Felipe III (1598-1621) marca un hito fundamental. Algunas de las medidas legislativas que impulsó tuvieron consecuencias decisivas para la población cristiana nueva de origen portugués y para el conjunto de las sociedades ibéricas. Es el caso del perdón general de 1605. El presente artículo, elaborado a partir de fuentes documentales inéditas, analiza las complejas negociaciones que se llevaron a cabo entre 1598 y 1607 al respecto. Negociaciones dirigidas por los ministros principales de la corte del rey y por los procuradores de los cristianos nuevos, con Lisboa, Valladolid y Madrid como escenario de las mismas.

Palabras Clave: Felipe III, cristianos nuevos portugueses, perdón general, 1605.

\section{SUMMARY}

Both in Spanish and in Portuguese history, the policy developed by Philip III (15981621) towards the Conversos represents a milestone. Some of the legislative measures driven by him did have deep consequences for the New Christian population of Portuguese origin as well as for the whole Iberian societies, as is the case of the "Perdón general" of 1605. This article, based on unpublished documentary sources, analyzes the intricate negotiations hold between 1598 and 1607, led by the main ministers of the royal court and the representatives of the New Christians in Lisbon, Valladolid and Madrid.

KeYwords: Philip III, Portuguese New Christians, "Perdón general”, 1605. 